\title{
Significados e sentidos da identidade musical de pacientes e familiares sob cuidados paliativos oncológicos*
}

Significances and meanings of the musical identity of patients and relatives receiving oncological palliative care

Significados y sentidos de identidad musical de pacientes bajo cuidados paliativos oncológicos y sus familiares.

Vladimir Araujo da Silva ${ }^{1}$, Neide Aparecida Titonelli Alvim², Sonia Silva Marcon ${ }^{3}$

\footnotetext{
* Extraído da Dissertação "Encontros musicais como recurso no cuidado de enfermagem em cuidados paliativos oncológicos: uma análise fenomenológica" apresentada ao Programa de Pós-Graduação em Enfermagem da Universidade Estadual de Maringá, no ano de 2011.

${ }^{1}$ Enfermeiro, Mestre em Enfermagem. Maringá, Paraná, Brasil. E-mail: vladimir araujo silva@hotmail.com.

2 Enfermeira, Doutora em Enfermagem. Professora Associada da Escola de Enfermagem Anna Nery da Universidade Federal do Rio de Janeiro. Rio de Janeiro

Rio de Janeiro, Brasil. E-mail: titonelli@globo.com.

${ }^{3}$ Enfermeira, Doutora em Filosofia da Enfermagem. Professora Associada do Centro de Ciências da Saúde da Universidade Estadual de Maringá. Maringá,

Paraná, Brasil. E-mail: ssmarcon@uem.br.
}

\section{RESUMO}

Pesquisa fenomenológica estruturada no referencial teórico-filosófico heideggeriano, que objetivou desvelar os significados e sentidos da identidade musical de pacientes e familiares sob cuidados paliativos oncológicos. Foram entrevistados, individualmente, 12 usuários (sete pacientes e cinco familiares) hospedados na casa de apoio da Rede Feminina de Combate ao Câncer de Maringá, que integraram oito encontros musicais realizados nos meses de janeiro e fevereiro de 2011. Apreendi que a identidade musical dos seres evidenciados reporta-se aos estilos musicais religioso e sertanejo, que os seus significados e sentidos estão atrelados à sua espiritualidade e aos eventos significativos de sua historicidade, e que o seu estado de espírito/humor e a reflexão intermediada pelas músicas podem influenciar a sua escolha musical. Evidencio a necessidade de se considerar a identidade musical e a autonomização na escolha musical, que traz consigo aspectos existenciais, sociais, culturais, espirituais e familiares, como elementos qualificadores do cuidado de Enfermagem em cuidados paliativos.

Descritores: Cuidados de Enfermagem; Enfermagem Oncológica; Música; Musicoterapia; Cuidados Paliativos.

\section{ABSTRACT}

This phenomenological study was structured on Heidegger's theoretical-philosophical framework, with the objective of unveiling the significances and meanings of the musical identity of patients and relatives under oncological palliative care. Individual interviews were performed with 12 clients (seven patients and five relatives) staying at the support residence of the Maringa Female Network Against Cancer. A total of eight musical meetings were performed between January and February of 2011. I understood that the musical identity of the evidenced beings refers to the religious and country music styles, that their significances and meanings are connected to their spirituality and the significant events of their historicity, and that their mood and reflection intermediated by music can influence their musical choice. I gave evidence to the need to consider the music identity and empowerment in musical choices, which carries existential, social, cultural, spiritual and family aspects as qualifying elements of nursing in palliative care.

Descriptors: Nursing Care; Oncology Nursing; Music; Music Therapy; Palliative Care.

\section{RESUMEN}

Investigación fenomenológica estructurada en referencial teórico-filosófico heideggeriano, objetivando revelar los significados y sentidos de identidad musical de pacientes bajo cuidados paliativos oncológicos y sus familiares. Fueron entrevistados individualmente 12 sujetos (siete pacientes, cinco familiares) hospedados en la residencia de apoyo de la Red Femenina de Combate al Cáncer de Maringá, participantes de ocho encuentros musicales realizados en enero y febrero de 2011. Aprendí que la identidad musical de las personas estudiadas remite a los géneros musicales religioso y "sertanejo", que sus significados y sentidos están vinculados a su espiritualidad y a eventos significativos de su historicidad, y que su estado de espíritu/humor y la reflexión mediada por las canciones pueden influir en sus elecciones musicales. Evidencio la necesidad de considerar la identidad musical y la autonomía en la elección musical, que trae consigo aspectos existenciales, sociales, culturales, espirituales y familiares, como elementos calificadores del cuidado de Enfermería

Descriptores: Atención de Enfermería; Enfermería Oncológica; Música; Musicoterapia; Cuidados Paliativos. 


\section{INTRODUÇÃO}

Os cuidados paliativos constituem uma filosofia de cuidado interdisciplinar que objetiva aprimorar a qualidade de vida de pacientes e famílias que vivem e convivem com doenças ameaçadoras de vida, nas dimensões física, psicológica, social e espiritual(1). Destarte, Enfermagem em cuidados paliativos constitui uma disciplina que articula a arte e ciência do cuidar de pessoas em processo de morte e morrer e suas famílias no processo de luto, no contexto da interdisciplinaridade, sob a ótica do cuidar/cuidado integral e relacional(2).

Nessa perspectiva, estruturadas nos pressupostos filosóficos dos cuidados paliativos, surgem inúmeras iniciativas como a utilização da música como recurso de cuidado, por sua contribuição multidimensional e por subsidiar o compartilhar de afetos, emoções e delicadezas, ou seja, a expressão de afetividade muitas vezes desapercebida ante a iminência de morte ${ }^{(3)}$. Uma revisão sistemática com meta-análise de 32 artigos acerca dos desfechos físicos e psicológicos de intervenções musicais em pacientes com câncer concluiu que a música pode melhorar a qualidade de vida, reduzir a ansiedade e a depressão, antes, durante e após os tratamentos antineoplásico, produzir efeitos positivos no manejo da dor, dentre outros(4).

Com o intuito de investigar uma intervenção que pudesse ampliar os recursos terapêuticos no cuidado de Enfermagem em oncologia, foram desenvolvidos Encontros Musicais como uma estratégia transdisciplinar que articulou Enfermagem, Musicoterapia e Atividade grupal multifamiliar no contexto da quimioterapia, alicerçada no paradigma da complexidade. Os resultados apontam que os encontros musicais podem influenciar o processo terapêutico e facilitar a comunicação cliente/familiar/enfermeiro ao proporcionar a integralidade do cuidado e a interação social, além de compor um ambiente de reflexão e reconstituição por meio da dialogicidade e da escuta sensível(5).

Estudo fenomenológico que objetivou compreender como os familiares percebem a influência da experiência musical na saúde física e mental de pacientes com câncer que experienciam a terminalidade da vida, desvelou que a música pode contribuir para o seu bem-estar, dando sentido aos seus dias; suscita sentimentos de alegria tornando-os mais comunicativos, como se a doença estagnasse na temporalidade e no espaço vivido; representa um suporte psicossocioespiritual que subsidia força e coragem na transcendência de sua angústia existencial ${ }^{(6)}$.
Outro estudo fenomenológico evidencia os encontros musicais como um recurso em cuidados paliativos oncológicos que pode inspirar vida aos dias de quem vive e convive com o câncer em uma casa de apoio, imprimindo-Ihes a sensação de cuidado, resignificando o existir no mundo com câncer e o coexistir no mundo com ele, além de dar sentido à razão de ser e estar em uma casa de apoio. Nesse contexto, a música pode intermediar a copresença entre os seres, subsidiando a possibilidade de estar com o outro em sua fatalidade existencial ${ }^{(7)}$.

Ressalto que a música pode promover alterações de comportamentos e estados de espírito, despertar sentimentos e sensações, inclusive modificar o estado de consciência. Não obstante, a musicologia sugere que os significados e sentidos da experiência musical pode estar relacionada aos elementos intrínsecos à música, ou aos elementos extrínsecos, dependendo, dentre outros, do modo como é vivenciada e do contexto sociocultural ao qual está inserida, desencadeando efeitos fisiológicos, psicofisiológicos, psicológicos, sociais, estéticos e existenciais nos seres humanos ${ }^{(8)}$.

Nesse sentido, a escolha musical reflete a própria identidade do ser humano, ou seja, a singularidade do seu existir. Por integrar sua cotidianidade, a música reaviva experiências emocionais pregressas, advindas de eventos importantes da vida, originando uma biografia musical intrínseca a cada ser humano. Valorizar sua apreciação musical significa respeitar sua personalidade, sua dignidade e seus direitos humanos ${ }^{(9)}$.

Um ensaio clínico randomizado acerca dos efeitos da musicoterapia na espiritualidade, realizado junto a 17 pacientes de uma unidade de oncologia/hematologia, evidenciou diferença significativa entre os grupos experimental e controle nos escores de fé e paz, com maior média no pós-teste do grupo experimental $(p<0,05)$. Sugere-se que a utilização da música de preferência do paciente pode promover bem estar espiritual e que o envolvimento ativo e o vínculo terapêutico podem servir como catalisadores para aumentar a espiritualidade ${ }^{(10)}$.

No Brasil, observo uma tendência atual da produção científica acerca da utilização da música no cuidado de Enfermagem a pessoas com câncer e seus familiares ${ }^{(5,11)}$, sobretudo no contexto dos cuidados paliativos e com abordagem fenomenológica(6-7). A partir desse pressuposto e das observações realizadas no decorrer da minha experiência com intervenções musicais estruturadas a partir da preferência musical dos pacientes, emergiu a seguinte inquietação: Quais são os significados e sentidos da identidade musical dos 
pacientes com câncer e familiares hospedados em uma casa de apoio?

Com efeito, vários estudos evidenciam a importância de valorizar a identidade musical dos pacientes, por meio de sua participação na escolha do repertório a ser implementado nas intervenções musicais, bem como os benefícios advindos de sua utilização(5-7,9-12). Contudo, o presente estudo objetivou desvelar os significados e sentidos da identidade musical de pacientes e familiares sob cuidados paliativos oncológicos, haja vista que os estudos supracitados não enfatizam a compreensão desses significados e sentidos, tampouco sob a ótica da fenomenologia existencial.

\section{MÉTODOS}

Para desvelar o fenômeno investigado, optei pela pesquisa qualitativa fenomenológica, tendo como referencial teórico-filosófico a fenomenologia existencial heideggeriana, que concebe a afinação ou tonalidade afetiva como um constitutivo ontológico do ser-aí, ou seja, da existência humana, que o permite revelar-se ao mundo(13). No que concerne à intervenção musical, o encontro intermediado pela música pode subsidiar o desvelar da afinação dos seres e incitar a sensação de ser cuidado diante das manifestações de solicitude do enfermeiro, dos efeitos terapêuticos da música e da oportunidade de poder expressar os seus sentimentos e compartilhar suas experiências de vida(7).

A região de inquérito desta pesquisa foi a subjetividade latente nas vivências dos usuários (pacientes e familiares) da casa de apoio da Rede Feminina de Combate ao Câncer (RFCC) de Maringá/Paraná - uma organização social, que acolhe usuários adultos de ambos os sexos, oriundos de outros municípios e estados, durante a realização do tratamento antineoplásico. Destaco que, independente do quadro clínico do paciente, a presença de um familiar acompanhante é permitida, mas não obrigatória.

Os critérios de inclusão foram: ser usuário adulto (paciente ou familiar) hospedado na casa de apoio da RFCC, e ter participado no mínimo de três encontros musicais. Os critérios de exclusão compreenderiam usuários que concluíssem o tratamento e retornassem para as suas cidades antes da realização das entrevistas, bem como os discursos que não contemplassem o objetivo proposto. O número de participantes foi delimitado no decorrer da análise dos dados, quando os discursos desvelaram o fenômeno investigado, ou seja, responderam as inquietações e os objetivos da pesquisa.
Para descrever a intervenção musical, adotei as diretrizes recomendadas para relatórios de intervenções musicais na área da saúde, considerando a complexidade de estímulos musicais, e outros fatores como a escolha da música, o modo de entrega, ou a combinação de música com outras estratégias ${ }^{(14)}$. Inicialmente, procedi com a etapa de familiarização com o cenário de estudo e aproximação dos usuários, momento em que eu me apresentei, disse que estaria realizando encontros musicais na casa de apoio, convidei a todos a participarem e procurei saber sobre suas preferências musicais, para melhor planejar a intervenção e contemplar a apreciação de todos.

Ressalto que valorizar a autonomia do cliente na escolha do repertório pode significar acolhimento e subsidiar o estabelecimento de relações e vínculos voltados para uma concepção humanizada do cuidado de Enfermagem ${ }^{(15)}$. Logo, as músicas foram pré-selecionadas pelos participantes, bem como pelo pesquisador, direcionado pelo estilo musical ou cantor, referenciados na abordagem inicial. Durante os meses de janeiro e fevereiro de 2011, foram realizados oito encontros musicais as segundas-feiras, com início às 17h30min e duração média de $1 \mathrm{~h} 30 \mathrm{~min}$. Esse cronograma fora estabelecido de modo a não interferir na rotina da instituição e oportunizar o recurso terapêutico a todos os usuários, considerando que no período da manhã e/ou da tarde, deslocavam-se para a clínica ou hospital para se submeterem ao tratamento antineoplásico.

A estratégia de intervenção utilizada foi a audição musical, associada ao processo expressivo e interativo dos pacientes e familiares. O modo de entrega musical foi música ao vivo - voz e violão. Para o desenvolvimento da estratégia foram utilizados: violão de seis cordas Tagina ${ }^{\circledR}$ Dallas com cordas de aço, uma estante de partituras Hunter ${ }^{\circledR}$, além de 10 cópias do material impresso em folhas de sulfite A4 brancas contendo as letras das músicas disponibilizadas aos participantes. Com o intuito de propiciar a interação social, as cadeiras e sofás da sala social da casa de apoio foram dispostos em círculo e as músicas foram executadas pelo primeiro autor enfermeiro e músico com experiência clínica pregressa com a participação dos usuários, e em volume agradável aos ouvidos.

No total, 33 usuários (20 pacientes e 13 familiares acompanhantes) integraram os encontros musicais, distribuídos conforme disposição apresentada no Quadro 1. Todavia, somente 12 usuários (sete pacientes e três familiares) foram incluídos na pesquisa. 
Quadro 1: Número de pacientes e familiares sob cuidados paliativos oncológicos por encontro musical implementado para o desenvolvimento da pesquisa. Maringá, PR, Brasil, 2011.

\begin{tabular}{|c|c|c|c|}
\hline \multirow{2}{*}{$\begin{array}{c}\text { Encontros } \\
\text { Musicais }\end{array}$} & \multicolumn{2}{|c|}{$\begin{array}{c}N^{\circ} \text { de pacientes e familiares por Encontro } \\
\text { Musical }\end{array}$} & $\begin{array}{c}\text { Total de participantes por Encontro } \\
\text { Musical }\end{array}$ \\
\cline { 2 - 4 } & Pacientes & 05 & 13 \\
\hline 1 & 08 & 03 & 14 \\
\hline 2 & 11 & 04 & 12 \\
\hline 3 & 08 & 05 & 17 \\
\hline 4 & 12 & 05 & 14 \\
\hline 5 & 09 & 03 & 11 \\
\hline 6 & 08 & 04 & 11 \\
\hline 7 & 07 & 03 & 07 \\
\hline
\end{tabular}

Após integrar os encontros musicais pela terceira vez, o usuário era convidado a participar da pesquisa, mediante leitura e assinatura do Termo de Consentimento Livre e Esclarecido (TCLE). Para a coleta de dados, utilizei a observação de campo e a entrevista individual, conduzida pela seguinte questão norteadora: o que esses encontros musicais representam para você neste momento de sua vida? Entretanto, para contemplar a finalidade deste estudo, no final da entrevista, procurei saber a música que os usuários mais gostaram de ouvir e o porquê, ou seja, os significados e sentidos de sua identidade musical.

As entrevistas foram realizadas nos aposentos de cada depoente - ambiente onde vivenciaram as nuances mais subjetivas de sua facticidade - gravadas e, posteriormente, transcritas na íntegra. Objetivando captar os significados e sentidos expressos pelos pacientes e familiares, adotei como referencial metodológico, os passos preconizados por Josgrilberg(16), ou seja, leituras atentivas das transcrições, precedendo a seleção fenomenológica dos discursos, separação dos trechos ou unidade de sentidos que satisfazem a interrogação ontológica, agrupando-as em temáticas ontológicas. As observações registradas em diário de campo enriqueceram a análise e discussão dos dados.

No processo hermenêutico, procurei identificar os quatro níveis de experiência musical descritos no modelo analítico elaborado por Ruud e Bonde ${ }^{(17)}$ : o fisiológico, que se refere às reações orgânicas ao som - propriedades físico-acústicas; o sintático, relacionado às regras e princípios gerais da estrutura musical, ou seja, ao fenômeno estético - experiência de coerência e beleza; o semântico, que está atrelado ao fenômeno existencial e espiritual, que envolve experiência de humor, relevância, significado e sentido; e o pragmático, o qual apresenta a música como processo e atividade interativa, vinculada ao fenômeno social e cultural, que abrange o lúdico, o ritual e a comunidade.

Enfatizo que a memória musical forma a identidade musical do ser, articulada à sua historicidade e cultura, e está vinculada aos espaços de identificação: pessoal, que abrange a consciência emocional e corporal, relacionado às crenças básicas; o social, que envolve o grupo de pertencimento (estilo, valores) e a comunidade; o tempo/lugar, voltado para os rituais diários, celebrações, fases da vida e nacionalidade; e o transpessoal, que está atrelado às experiências religiosas, rituais de transição, natureza e sentido de "ser maior"(9). Estes espaços de identificação também foram utilizados na análise e interpretação dos dados.

Com o intuito de garantir o anonimato dos pacientes e familiares, utilizei como pseudônimos nomes de andamentos musicais - Grave, Largo, Larghetto, Adágio, Andante, Andantino, Allegretto, Moderato, Allegro, Vivace, Presto, Prestissimo - precedidos pelas iniciais $\mathrm{P}$ ou $\mathrm{F}$, identificando-os, respectivamente, como paciente ou familiar, sucedidos por sua idade em anos.

Por se tratar de uma pesquisa de campo, foram observados os aspectos éticos regulamentados pela Resolução 196/96 do Conselho Nacional de Saúde Ministério da Saúde (MS). O projeto de pesquisa foi apreciado e aprovado pelo Comitê Permanente de Ética em Pesquisa Envolvendo Seres Humanos (COPEP) da Universidade Estadual de Maringá - UEM, Parecer $n^{\circ}$. 614/2010, após autorização prévia da RFCC.

\section{RESULTADOS E DISCUSSÃO}

A escolha musical dos pacientes e familiares (músicas, cantores ou estilos musicais referenciados na abordagem inicial), as músicas propostas pelo pesquisador, bem como as músicas e estilos musicais que compuseram sua identidade musical nos encontros musicais, estão apresentadas no Quadro 2. 
Quadro 2. Escolha musical, músicas propostas pelo pesquisador e identidade musical de pacientes e familiares sob cuidados paliativos oncológicos. Maringá, PR, Brasil, 2011.

\begin{tabular}{|c|c|c|c|}
\hline $\begin{array}{l}\text { Pacientes e } \\
\text { familiares }\end{array}$ & Escolha musical & $\begin{array}{c}\text { Músicas propostas pelo } \\
\text { pesquisador }\end{array}$ & Identidade musical \\
\hline F. Grave, 29 & Couro de boi & - & Tristeza do Jeca \\
\hline F. Largo, 48 & Música sertaneja & Tristeza do Jeca & Oração pela família* \\
\hline P. Larghetto, 40 & Música sertaneja & Chalana & Música religiosa \\
\hline \multirow{2}{*}{ P. Adágio, 66} & \multirow{2}{*}{ Meu reino encantado } & \multirow[b]{2}{*}{-} & Música religiosa \\
\hline & & & Meu reino encantado \\
\hline \multirow{2}{*}{ P. Andante, 66} & \multirow{2}{*}{ Victor e Léo } & \multirow{2}{*}{ Borboletas } & Música religiosa \\
\hline & & & Segura na mão de Deus \\
\hline P. Andantino, 72 & Música antiga & Cabocla Tereza & Segura na mão de Deus \\
\hline P. Allegretto, 62 & $\begin{array}{c}\text { No dia em que eu saí de } \\
\text { casa }\end{array}$ & - & $\begin{array}{c}\text { No dia em que eu saí de } \\
\text { casa }\end{array}$ \\
\hline F. Moderato, 43 & Música religiosa & Noite traiçoeira & Segura na mão de Deus \\
\hline \multirow{2}{*}{ F. Allegro, 53} & \multirow{2}{*}{ Música religiosa } & \multirow{2}{*}{ Deus enviou } & Música religiosa \\
\hline & & & Franguinho na panela \\
\hline \multirow{2}{*}{ P. Vivace, 47} & \multirow{2}{*}{ Música religiosa } & \multirow{2}{*}{ Grandioso és Tu } & Segura na mão de Deus \\
\hline & & & O ipê e o prisioneiro \\
\hline F. Presto, 27 & Música religiosa & Segura na mão de Deus & Noite traiçoeira \\
\hline P. Prestissimo, 74 & Música religiosa & Te amarei Senhor & Música religiosa \\
\hline
\end{tabular}

Nota: ${ }^{*}$ Música referenciada por um usuário que integrou os encontros musicais, mas que não foi incluído na pesquisa.

Observei que houve, tanto na escolha musical quanto na identidade musical, a prevalência dos estilos musicais, religioso e sertanejo, com ritmos quaternário e ternário. Durante o processo de compreensão do fenômeno, notei que as unidades de sentido eram convergentes e, portanto, foram agrupadas em uma temática existencial abrangente, capaz de organizá-las em si - Desvelando os significados e sentidos da identidade musical. As unidades de sentido foram articuladas com alguns pensamentos heideggerianos, bem como de outros autores que versam sobre a temática.

\section{Desvelando os significados e sentidos da identidade musical}

Na concepção heideggeriana, o ser humano é um serno-mundo que existe sempre em relação com algo ou alguém e nesse estado compreende suas experiências, resignificando os entes e seres ao seu redor, dando sentido à sua existência. Tudo o que percebemos, entendemos ou conhecemos de imediato, é ôntico ou existenciário. Deste modo, os utensílios ou objetos não são meramente entes "ante os olhos", "à mão", pois inclui em seu ser uma referência ontológica, ou seja, estão essencialmente disponíveis para um uso determinado, satisfazer as necessidades emergentes do ser-nomundo(13).
Nessa perspectiva, a música constitui um existenciário que, por meio dos encontros musicais, permite ao ser-aí desvelar os significados e sentidos de sua identidade musical e existencial. Um dos princípios básicos que regem a utilização da música no cuidado de Enfermagem, o de caráter ontológico, reporta-se às experiências sonoro-musicais do ser-aí, que encerram sua essência humana - ser um ser musical(18).

Com efeito, para compreender a significação musical, torna-se imprescindível resgatar a historicidade do ser-aí, por meio do discurso verbal acerca de suas experiências musicais, haja vista que os significados e sentidos repercutem em suas vivências e emergem do contato com a música ao longo de sua vida. Logo, esses significados são constituídos de sentidos, atrelados às peculiaridades da intervenção musical(19), conforme observei nas unidades de sentido a seguir.

Eu amo "Tristeza do jeca" (risos). É essa música que eu gosto mais, das que a gente cantou. Não sei... acho que ela toca bastante assim, o jeito (F. Grave, 29).

A música é bem vinda em todos os lugares e eu sou uma pessoa muito eclética. Eu gosto de tudo quanto é gênero de música. [...] Mas, a música que eu gostaria de ter a letra e de ter várias pessoas cantando ao mesmo tempo, é a Família - Oração pela família. Eu acho uma música 
muito bonita e que tem muito a ver com o casal [...] são palavras bonitas, são frases maravilhosas e que se você prestar a atenção, realmente, a música inteira tem o significado da pura realidade do ser humano (F. Largo, 48).

A escolha musical de Grave, o seu discurso e, sobretudo, o conteúdo intrínseco em sua identidade musical, transmitem a simplicidade do seu existir. A letra da música "Tristeza do Jeca" retrata algumas peculiaridades da vida no campo, um cenário familiar à jovem agricultora. Apreendi de suas palavras, os níveis de experiências musicais, sintático e semântico (experiências de coerência e humor), e os espaços de identificação pessoal, social e tempo/lugar ao correlacionar seus aspectos culturais à letra da música.

Em sua linguagem, Largo acolhe os encontros musicais, evidenciando a música em seu espaço de identificação tempo/lugar, quando descreve que ela é "bem-vinda em todos os lugares". Embora aprecie outros estilos musicais, referenciou músicas sertanejas quando foi solicitada sua preferência musical, sugerindo o nível de experiência sintático - fenômeno estético. No entanto, em relação ao repertório constituído da apreciação do grupo, elegeu a música "Oração pela família" pela beleza e representatividade de sua estrutura poética, isto é, o nível de experiência semântico e o espaço de identificação pessoal.

A escolha musical de Largo revela sua concepção de amor, de família e de ser humano. Percebi em seu depoimento, a relevância dos encontros musicais em sua temporalidade quando alude que gostaria de "ter várias pessoas cantando ao mesmo tempo", demonstrando o significado que a co-presença e o coro formado por diferentes timbres, ecoa em sua existencialidade, decifrando o nível de experiência pragmático e o espaço de identificação social. Enfatizo que as intervenções musicais em grupo podem agregar valores em termos de suporte aos participantes e que os efeitos terapêuticos das interações sociais a ele inerentes, podem transcender os da própria intervenção(14).

Outro princípio básico utilizado pela Enfermagem, o de caráter relacional, reflete a relação entre o ser-aí compositor e o ente música, mas, sobretudo o encontro mediado pela música no contexto do cuidado à saúde, decorrente da intencionalidade de cuidar, que possibilita a demonstração de afetividade, compaixão e solidariedade, por meio de gestos, olhares, sorrisos e toques suaves inerentes à execução musical(18).
Tem música que toca no emocional de cada um. [...] quando vem em parte religiosa, falando de Deus [...] A princípio eu gosto de todas as músicas, mas as religiosas, são as que nesses encontros, tocam mais ( $P$. Larghetto, 40).

Esses hinos religiosos... Isso aí comove muito a gente, deixa a gente bastante confortado (P. Adagio, 66).

Ai esses hinos maravilhosos que você canta. Aquele mesmo, "Segura na mão de Deus" é o que a gente tem que fazer para conseguir sobreviver. [...] Na hora do hino é tão lindo, tão confortante para a gente... sabe? Fica aquela paz gostosa... na vida da gente. Gosto de música sertaneja, eu adoro, mas quando chega a hora daquele hino, é maravilhoso, escutar... você cantar, todo mundo cantando junto. É muito gostoso. E eu nem canto porque se eu cantar, eu vou chorar igual eu estou chorando agora (P. Andante, 66).

"Segura na mão de Deus". Porque eu amo essa música, ela me toca demais. Essa música para mim é tudo. Toda vida eu gostei e quando você canta ela, a gente se transforma em outra pessoa (P. Andantino, 72).

Na descrição da linguagem de Larghetto reconheci os níveis de experiências musicais sintático e semântico e os espaços de identificação pessoal e transpessoal, quando discorre sobre a diversidade de sua apreciação musical e a relevância das músicas religiosas nos encontros musicais, respectivamente. Da mesma forma, identifiquei no discurso de Adágio, o nível de experiência semântico e os espaços de identificação pessoal e transpessoal, ao enfatizar a comoção e o conforto experienciados ao ouvir os hinos que compunham o repertório implementado.

A fala de Andante revela os níveis de experiência semântico, sintático - apreciação dos estilos musicais sertanejo e religioso - e especialmente o fisiológico, quando explana "eu nem canto porque se eu cantar, eu vou chorar igual eu estou chorando agora", bem como os espaços de identificação pessoal, social e transpessoal. No depoimento de Andantino, reconheci os níveis de experiência sintático e semântico, destacando a influência da música "Segura na mão de Deus" em sua temporalidade existencial, denotando os espaços de identificação pessoal e tempo/lugar, sobretudo sua experiência transcendental nos encontros musicais, quando descreve "a gente se transforma em outra pessoa" que constitui o espaço de identificação transpessoal.

O princípio de caráter musical, utilizado pela Enfermagem, está relacionado aos elementos musicais inerentes à intervenção musical proposta, que podem estar atrelados à dimensão física, como o ritmo, à 
dimensão emocional, como a melodia, à dimensão social, como o contexto histórico-cultural no qual se origina, ou à dimensão espiritual, cujos elementos musicais convergem para articular todas as dimensões humanas, subsidiando uma experiência transcendental ${ }^{(18)}$.

Ao identificar os níveis de experiências musicais e os espaços de identificação dos pacientes e familiares, compreendi a importância da dimensão espiritual do cuidado e o quanto a reflexão mediada pelas músicas religiosas resignificou sua existencialidade, pois, na angústia e na incerteza de seu porvir (futuro), emerge a necessidade de se aproximar de Deus, para suportar as consternações vivenciadas, encontrando na música, conforto e paz interior. Apreendi que a sensação de prazer, experienciada ao ouvir uma música que traz consigo significados existenciais, conduz o ente à renovação do seu ser.

Corroborando, a experiência do sofrimento oferece ao ser-aí a possibilidade de transformar sua própria existência, resignificando sua trajetória existencial(20).

Contextualizando, as sessões musicais estruturadas a partir da preferência musical de idosos com Doença de Alzheimer de uma instituição de longa permanência, possibilitou a evocação de reminiscências afetivas remotas e recentes, relacionadas à história de vida pessoal e familiar, lugares e situações vivenciadas, integrando-os à realidade, permitindo-lhes acessar suas memórias musicais, sugerindo que estas permanecem preservadas $^{(12)}$, assim como pude perceber nos depoimentos a seguir.

Representa saudade de quando a gente morava no sítio. Então, é aquela tradição antiga... Representa muito na vida da gente (P. Adagio, 66) - refere-se à música "Meu reino encantado".

... as músicas que tocam muito na vida da gente, no passado. [...] No dia em que eu saí de casa", que é familiar mesmo e... a gente já passou por isso. O filho da gente vai crescendo e, vai sumindo... um pouco da gente. $A$ gente fica sozinho, vai só lembrando daquilo ( $P$. Allegretto, 62).

Teve um momento especial, na música "Segura na mão de Deus" [...] Aquele momento marcou bastante. Eu vi uma amiga minha que desceu as lágrimas, a Vivace. [...] E teve uma outra que foi muito legal, inclusive eu me apeguei muito na Vivace. É uma música que ela gostava bastante. Então, eu acabei gostando desse momento, por ver a Vivace feliz (F. Moderato, 43).

Todos os dias que tem o encontro é especial... Seja qual música for... Se for sobre Deus é melhor ainda [...] Ah! esse "Franguinho na panela" doeu, hein? E a gente lembra da família... O tanto que o pai lutou, o tanto que o marido lutou... E depois você vê assim, fala: nossa!!! O "Franguinho na panela" judia, hein? (risos) (F. Allegro, 53).

Nesta unidade de sentidos, Adágio revela o nível de experiência musical semântico e os espaços de identificação tempo/lugar, pessoal e social quando narra a representatividade de suas raízes histórico-culturais. $\mathrm{Na}$ linguagem de Allegretto distingui o nível de experiência semântico e os espaços de identificação tempo/lugar, pessoal e social, quando discorre sobre o seu vigor de ter sido (passado), sobretudo quando relaciona sua historicidade familiar à letra da música "No dia em que eu saí de casa". No decorrer dos encontros musicais, também compartilhou com o grupo o vazio existencial experienciado na ausência do filho que estava nos Estados Unidos há oito anos.

Na unidade de sentido emergente do depoimento de Moderato vislumbrei os níveis de experiência semântico e pragmático, e os espaços de identificação social e tempo/lugar, pois alude os fenômenos existencial e social inerentes à intervenção musical proposta, denotando que sua identidade musical surgiu das relações estabelecidas em sua temporalidade na casa de apoio - princípio relacional da música.

Já no discurso de Allegro, identifiquei o nível de experiência sintático (fenômeno estético), mas principalmente o semântico, pois quando descreve "Se for sobre Deus é melhor ainda", refere-se ao fenômeno existencial, espiritual experienciado. Também reconheci o nível de experiência fisiológico quando se reporta à "dor" sentida ao ouvir "Franguinho na panela" e reavivar experiências familiares pregressas, bem como os espaços de identificação pessoal, tempo/lugar, social e transpessoal. No diário de campo também foi registrado o momento em que sua "dor" se manifestou, pois durante a música supracitada, Allegro deixou o ambiente de cuidado com os olhos rasos d'água, permaneceu do lado de fora da casa de apoio por alguns minutos, pois não conseguiu conter a emoção sentida naquele momento.

Quando retornou, com os olhos avermelhados, preferiu não compartilhar suas lembranças com o grupo. Contudo, durante a entrevista, revelou o desgosto de presenciar o extenuar de seu marido e a incerteza de seu porvir. A tonalidade afetiva de Allegro nos adverte quanto a importância de divulgarmos estratégias terapêuticas como os encontros musicais, que contribuem para a redução da angústia relacionada à morte durante o 
tratamento antineoplásico(11). Enfatizo que o significado de uma música pode estar vinculado às experiências relacionadas a um devir ${ }^{(19)}$.

Nesse contexto, ao despertar para a possibilidade irremissível e insuperável da impossibilidade, ou seja, do não existir, o ser humano desvela-se como um ser de preocupação consigo mesmo e para com outros entes ao seu redor ${ }^{(13)}$. Entretanto, ao descobrir ser um ser-para-amorte, se entristece perante a possibilidade do não pensado, do não planejado, ou seja, a mais inevitável de suas certezas, a morte.

Indiscutivelmente é muito mais prazeroso ouvirmos o que agrada nossos ouvidos ou que compõe nossa biografia musical, reavivando momentos agradáveis, a ouvirmos sons desconexos de nossas vivências, ou que evocam lembranças desagradáveis. Todavia, como os encontros musicais são realizados em grupo, o ser-aí está sujeito a ouvir alguma música, escolhida por outro ser-aí, que desperta em seu âmago sentimentos de tristeza, ao reavivar lembranças imêmores em sua temporalidade, como aconteceu com Allegro e Vivace. Saliento que o modo como percebemos e somos afetados pelos estímulos sonoro-musicais conduzidos através do nervo auditivo até o córtex, e que desencadeia respostas sensoriais fisiológicas, mentais e emocionais - constitui o princípio de caráter físico (vibracional) utilizado pela Enfermagem(18).

Ontem eu estava assim... triste. Então, até que eu falei que não queria cantar. Em outros encontros eu cantei e não tive problema, mas [...] Não sei se porque ontem eu já estava sensível, eu já tinha passado uma semana... triste. Então, ela mexeu assim... ela me fez ir lá naquele dia... Não é que eu não queria, mas... ontem não ia me fazer bem ficar ali, entendeu? ( $P$. Vivace, 47).

O discurso de Vivace correlaciona com os níveis de experiências musicais fisiológico e semântico experiência de humor e significado - e os espaços de identificação tempo/lugar e pessoal. Assim, apreendi que os significados e sentidos musicais podem estar atrelados ao estado emocional do ser-aí, ou seja, quando este se encontra emocionalmente vulnerável, a música que outrora ouviu e cantou sorrindo, nos faz chorar e por isso, evita ouvi-la. Por esta razão, quando alguém escolheu a música "Segura na mão de Deus", Vivace deixou o ambiente de cuidado, ao pressentir sua fragilidade emocional naquele momento.

Estudo sueco sobre evidências experimentais acerca da influência da escolha musical, do contexto social e da personalidade do ouvinte nas reações emocionais à música, realizado com 50 estudantes universitários, sugere que as emoções são mais intensas quando a música é autoescolhida ou quando se ouve na presença de um amigo ou parceiro, em detrimento da seleção musical aleatória e da audição musical individual. Todos os três fatores foram correlacionados positivamente com experiências de emoções positivas como felicidade e $\operatorname{prazer}^{(21)}$.

Contextualizando o pressentimento de Vivace, a fenomenologia da percepção contempla a integralidade do corpo, bem como sua relação com as coisas que estão aí, ou seja, o sentido é algo percebido no próprio corpo, pois este constitui um imbricado conjunto de significações vivas - percepções táteis, visuais e auditivas - que participam sempre de um movimento, no sentido de seu equilíbrio(22).

... Eu até ia pedir para você me dar a letra, porque eu gostei muito [...] é uma musiquinha bonitinha, aquela do ipê florido - O ipê e o prisioneiro. Eu gosto muito dela (risos) [...] Eu nunca tinha ouvido aquela música, e ela foi assim... Não sei. Essa música vai me marcar ( $P$. Vivace, 47).

Nesta unidade de sentido, Vivace manifesta os níveis de experiências musicais sintático e semântico, quando descreve a singeleza (fenômeno estético) e a representatividade da música em sua vida (fenômeno existencial e espiritual), bem como sua consciência emocional (espaço de identificação pessoal).

No depoimento de Presto, identifiquei os espaços de identificação tempo/lugar, pessoal e transpessoal, quando nos remete à sua temporalidade existencial - nível de experiência semântico - e ao sentido encontrado na mensagem transmitida pela letra da música "Noite traiçoeira", que conforta ao dizer que a presença de Deus é real em sua vida e que, mesmo que o mundo possa fazêla chorar, Ele a quer sorrindo. Assim, desvelei que o serno-mundo se identifica com determinada música, ou seja, reconhece sua história de vida nos elementos que a compõe, neste caso, especialmente, o texto.

"Noite traiçoeira". Porque, essa música fala tudo... em tudo o que eu estou passando. E foi a descoberta que eu tive, que... Deus... me deu motivo para eu viver, deu motivo para eu lutar pela felicidade... [...] E ela conta a minha... bem dizer ela conta... o relato da minha vida Noite traiçoeira - E foi o que aconteceu (F. Presto, 27). 
Outro constitutivo ontológico do ser-aí é sua capacidade de transcender a si mesmo, projetar-se para além de si e descobrir o seu próprio sentido de estar-nomundo(13). Destarte, os significados e sentidos da experiência musical vivenciada por Prestissimo, nos encontros musicais, conduziram-na à superação de suas limitações e à resignificação de sua existência.

Ah! Eu não lembro o nome da música [...] Porque, eu não falei pra você que eu não cantava [...] nunca cantei na minha vida! Eu fui cantar aquele dia que você apareceu aqui! Então, eu não tenho nenhuma "decor" ( $P$. Prestissimo, 74).

Embora a memória de Prestissimo não tenha arquivado o nome da música com a qual se identificou, vislumbrei em sua linguagem o quanto os encontros musicais e a contemplação de sua apreciação musical foram significativos em sua experiência transcendental, evidenciando o nível de experiência musical semântico e todos os espaços de identificação - pessoal, social, tempo/lugar e transpessoal - especialmente quando proferiu Aqui que eu fui liberta em nome de Jesus. Louvando a Deus e cantando [...] De hoje em diante eu vou cantar, sugerindo que sua identidade musical advém das músicas religiosas que ouviu e cantou durante os encontros musicais.

\section{CONCLUSÃO}

Os significados e sentidos da identidade musical dos pacientes e familiares sob cuidados paliativos oncológicos, hospedados na casa de apoio retromencionada, estão atrelados à sua espiritualidade e aos eventos significativos de sua historicidade, inclusive às relações afetivas estabelecidas na casa de apoio. O seu estado de

\section{REFERÊNCIAS}

1. Wolrd Health Organization (WHO). WHO Definition of Palliative Care [Internet]. 2013 [update 2013, cited 2013 nov 13].

Available from:

http://www. who.int/cancer/palliative/definition/en/.

2. Silva RS, Silva MJP. Enfermagem e os cuidados paliativos. In: Silva RS, Amaral JB, Malagutti W. Organizadores. Enfermagem em cuidados paliativos: cuidando para uma boa morte. São Paulo: Martinari; 2013. p. 3-35.

3. Seki NH, Galheigo SM. O uso da música nos cuidados paliativos: humanizando o cuidado e facilitando o adeus. Interface (Botucatu) [Internet]. 2010; 14(33):273-84. [citado 2013 nov 13]. Disponível em:

http://www.scielo.br/pdf/icse/v14n33/a04v14n33.pdf.

4. Zhang JM, Wang P, Yao J, Zhao L, Davis MP, Walsh D, et al. Music interventions for psychological and physical outcomes in cancer: a systematic review and meta-analysis. Support Care Cancer. 2012; 20:3043-53. espírito/humor e a reflexão intermediada pelas músicas, podem influenciar sua escolha musical, pois alguns usuários ao integrarem os encontros musicais escolheram músicas sertanejas, inerentes ao seu contexto sociocultural, mas após os encontros musicais, implementados em um contexto de fragilidade, dor, angústia e sofrimento, revelaram outra realidade, onde as músicas religiosas sobressaíram, encantando e disseminando conforto e bem-estar, auxiliando nas estratégias de enfrentamento e na transcendência do seraí.

Reconheço as limitações desta pesquisa que, por sua natureza qualitativa, bem como pela restrição de sua abrangência a uma casa de apoio específica, a impede de generalizar os resultados obtidos. Contudo, evidencio a necessidade de se considerar a identidade musical como elemento qualificador do cuidado de Enfermagem, na elaboração e implementação de intervenções musicais no contexto dos cuidados paliativos, bem como a sensibilidade que o enfermeiro deve ter ao delinear o seu plano de cuidados na intencionalidade de cuidar do ser humano em condições ameaçadoras da vida e de seus familiares.

Ao valorizar a autonomização do ser-aí, traduzida por meio de sua escolha musical, que traz consigo aspectos existenciais, sociais, culturais, espirituais e familiares, 0 enfermeiro pode oferecer um cuidado integral, estimulando a expressão de percepções, emoções e vivências subjacentes à experiência musical aprimorando sua qualidade de vida e humanizando o cuidado na terminalidade da vida. Espero que os resultados incitem novas reflexões, sobretudo a realização de estudos experimentais acerca da utilização da música como recurso complementar no cuidado de Enfermagem em cuidados paliativos.

5. Bergold LB, Alvim NAT. Influência dos encontros musicais no processo terapêutico de sistemas familiares na quimioterapia. Texto Contexto Enferm. 2011; 20 (Esp):108-16.

6. Sales CA, Silva VA, Pilger C, Marcon SS. Music in human terminality: the family members' conceptions. Rev Esc Enferm USP [Internet]. 2011 [cited 2013 nov 13];45(1):134-40. Available from:

http://www.scielo.br/pdf/reeusp/v45n1/en_19.pdf. users of a support homes. Rev. Esc. Enferm. USP [Internet]. 2013 [cited 2013 nov 13];47(3):626-33. Available from: http://www.scielo.br/pdf/reeusp/v47n3/en_0080-6234-reeusp47-3-00626.pdf.

8. Sampaio RT, Sampaio ACP. Musicoterapia e cuidados paliativos. In: Santos FS, editor. Cuidados paliativos: diretrizes, humanização e alívio de sintomas. São Paulo: Atheneu; 2011, p. 245-50.

9. Ruud E. Music Therapy: Improvisation, Communication and Culture. Barcelona: Publisher; 1998. 
10. Cook EL, Silverman MJ. Effects of music therapy on spirituality with patients on a medical oncology/hematology unit: a mixed-methods approach. The Arts in Psychotherapy. 2013; 40:239-44.

11. Bergold LB, Lima R, Alvim NAT. Encontro musical: estratégia de cuidado de enfermagem em quimioterapia para discutir adoecimento/morte. Rev. enferm. UERJ. 2012; 20(esp.2):75863.

12. Albuquerque MCS, Nascimento LO, Lyra ST, Trezza MCSF, Brêda MZ. Os efeitos da música em idosos com doença de Alzheimer de uma instituição de longa permanência. Rev. Eletr. Enf. [Internet]. 2012 [cited 2013 nov 13];14(2):404-13. Available from:

http://www.fen.ufg.br/fen revista/v14/n2/pdf/v14n2a21.pdf. 13. Heidegger M. Ser e Tempo. 3. ed. Petrópolis: Vozes; 2008 14. Robb SL, Burns DS, Carpenter JS. Reporting guidelines for music-based interventions. J Health Psychol. 2011;16(2):342-52. 15. Bergold LB, Alvim NAT. Visita musical como uma tecnologia de cuidado. Texto \& contexto enferm. 2009;18(3):532-541. 16. Josgrilberg RS. A fenomenologia como novo paradigma de uma ciência do existir. In: Pokladek DD. (Org.). A fenomenologia do cuidar: prática dos horizontes vividos na área da saúde, educacional e organizacional. São Paulo: Vetor; 2004. p. 31-52. 17. VIII Encontro Nacional de Pesquisa em Musicoterapia. Analisando a música em musicoterapia - improvisações e composições: uma visão de métodos quantitativos e qualitativos (curso); 2008. In: Bergold LB. Encontros musicais: uma estratégia de cuidado de enfermagem junto a sistemas familiares no contexto da quimioterapia [tese]. [Rio de Janeiro]: Escola de Enfermagem Anna Nery/UFRJ; 2009. 240 p.

18. Leão ER, Puggina AC, Gatti MFZ, Almeida AP, Silva MJP. Música e Enfermagem: um recurso integrativo. In: Salles LF, Silva MJP. Enfermagem e as práticas complementares em saúde. São Caetano do Sul, SP: Yendis Editora; 2011, p. 155-74.

19. Wazlawick P, Camargo D, Maheirie K. Significados e sentidos da música: uma breve "composição" a partir da psicologia histórico-cultural. Psicol. estud. 2007;12(1):105-13. 20. Vieira GB, Silva RMCRA, Pereira ER, Silva MA. Os sentimentos dos clientes oncológicos: uma compreensão existencial da angústia em Heidegger. Rev Enferm UFPE. 2009;3(4):393-400.

21. Liljeström S, Juslin PN, Västfjäll D. Experimental evidence of the roles of music choice, social context, and listener personality in emotional reactions to music. Psychology of Music. 2013; 41(5):579-99.

22. Merleau Ponty M. Fenomenologia da percepção. Trad. Carlos Alberto Ribeiro de Moura. 3. ed. São Paulo: Martins Fontes; 2006.

Artigo recebido em 18/10/12.

Aprovado para publicação em 11/11/13

Artigo publicado em 31/03/2014. 